\title{
Anomalous pulmonary venous drainage shown by duplex sonography, computed tomography, and plain radiography
}

\author{
PETER HUEBSCH, ANDREAS NEUHOLD, HARALD MAYR, DIETMAR GLOGAR
}

From the Division of Diagnostic Radiology, Second Department of Medicine, and the Department of Cardiology, University of Vienna, and the Institute for Diagnostic Imaging of the Rudolfinerhaus Hospital, Vienna, Austria

ABSTRACT In a patient with the scimitar syndrome duplex Doppler sonography was used to show the point of entry of the abnormal pulmonary vein into the inferior vena cava to determine blood flow. Chest radiography and computed tomography also showed the vein descending to the diaphragm.

\section{Introduction}

Several forms of partial and total anomalous pulmonary venous drainage have been described,' including the scimitar syndrome, which was first described by Cooper in $1836 .^{2}$ In this condition the anomalous vein is usually visible on the plain posteroanterior radiograph as a broad, gently curved shadow descending to the diaphragm to the right of the heart. ${ }^{1-3}$ Because the radiological appearance of the vein resembles a Turkish sword, the term "scimitar syndrome" was introduced by Neill et al in 1960."

The abnormal vein usually drains a variable amount of blood from the right lung into the inferior vena cava, thus constituting an extracardiac left to right shunt. ${ }^{1-3}$ In some cases there is drainage to the right atrium, the superior vena cava, or the azygos system. More than one anomalous vein may be present, ${ }^{s}$ as may other cardiopulmonary anomalies. ${ }^{125}$ The incidence of the scimitar syndrome is not known as patients are often symptomless. ${ }^{6}$ Symptoms may be due to associated malformations or to the anomalous venous connection itself. ${ }^{2}$ Presentation in infancy is rare, though cardiac failure, cyanosis, cardiac murmurs, and failure to thrive may occur. - $^{-8}$

Although the scimitar vein is visible on the chest radiograph in many cases, ${ }^{36}$ additional diagnostic procedures (including catheter studies) are often necessary to confirm the diagnosis and to evaluate any

Address for reprint requests: Dr Peter Huebsch, Division of Diagnostic Radiology, 2nd Department of Medicine, University of Vienna, A-1090 Vienna, Austria.

Accepted 20 October 1988 associated malformations. Recently a few cases have been reported in which computed tomography was helpful. ${ }^{69}{ }^{10}$ To our knowledge, duplex sonography has not been used to demonstrate the entry of the anomalous vein into the inferior vena cava.

\section{Case report}

A woman aged 66 years was admitted to hospital because of dyspnoea and moderate oedema of the legs. Her medical history included implantation of a pacemaker one year before in another hospital and a right mastectomy for breast cancer 16 years previously.

Physical examination showed moderate enlargement of the liver. She had a soft pansystolic murmur in the right parasternal region, a normal first heart sound, and fixed splitting of the second heart sound.

Echocardiography disclosed enlargement of the right atrium and the right ventricle. The Doppler examination showed incompetence of the tricuspid valve.

The chest radiograph (fig 1) showed right heart enlargement. On the lateral view an atypical vessel was seen projecting over the heart silhouette, descending to the diaphragm. On the posterior view the vessel was seen only faintly, near the right cardiophrenic angle. The lung fields were of normal appearance.

Sonography of the abdomen showed moderate distension of the inferior vena cava. The atypical vessel was seen entering the inferior vena cava immediately below the diaphragm. Venous flow signals were recorded within the vessel lumen by duplex sonography (fig 2). 

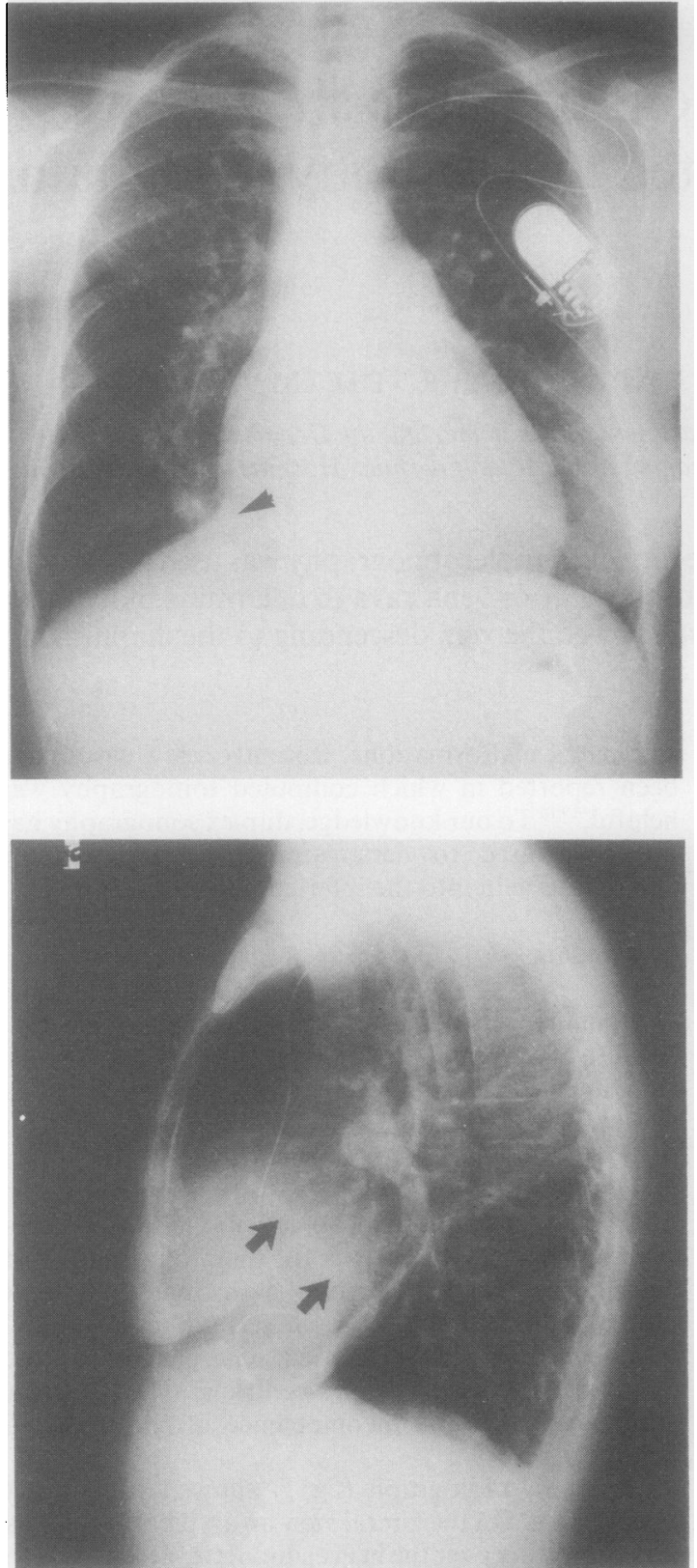

Fig 1 (Above) Posteroanterior chest radiograph with the vessel ill defined on the right side of the heart shadow (arrowhead).

(Below) Lateral chest radiograph with the scimitar vein clearly visible (arrows); near the diaphragm the vein can be seen on the original film by using a spotlight.

Cardiac catheterisation showed no septal defect; an oxygen step was detected in the inferior vena cava, indicating the presence of a left to right shunt $(1: 2 \cdot 7)$.

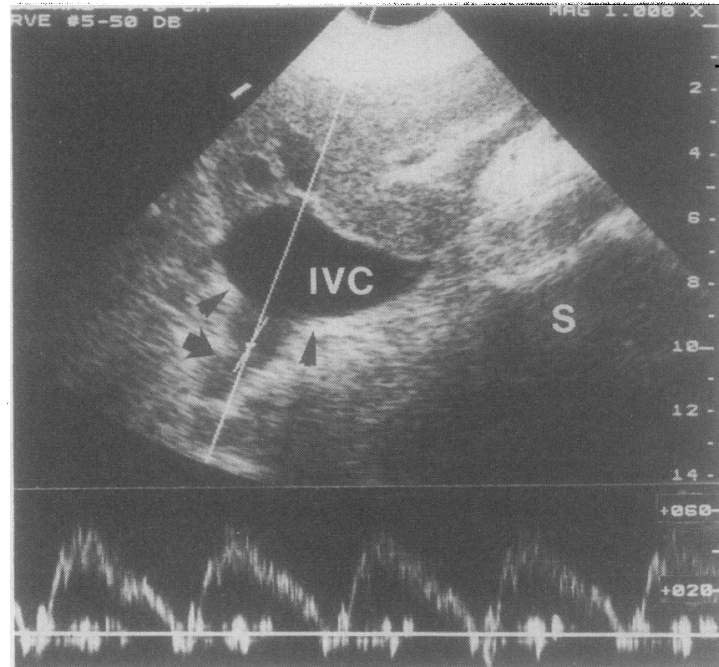

Fig 2 Duplex sonography of the scimitar vein (arrow) entering the inferior vena cava (IVC): venous flow with a peak velocity of nearly $0.6 \mathrm{~m} / \mathrm{s}$. S-spine; arrowheads indicate the diaphragm.

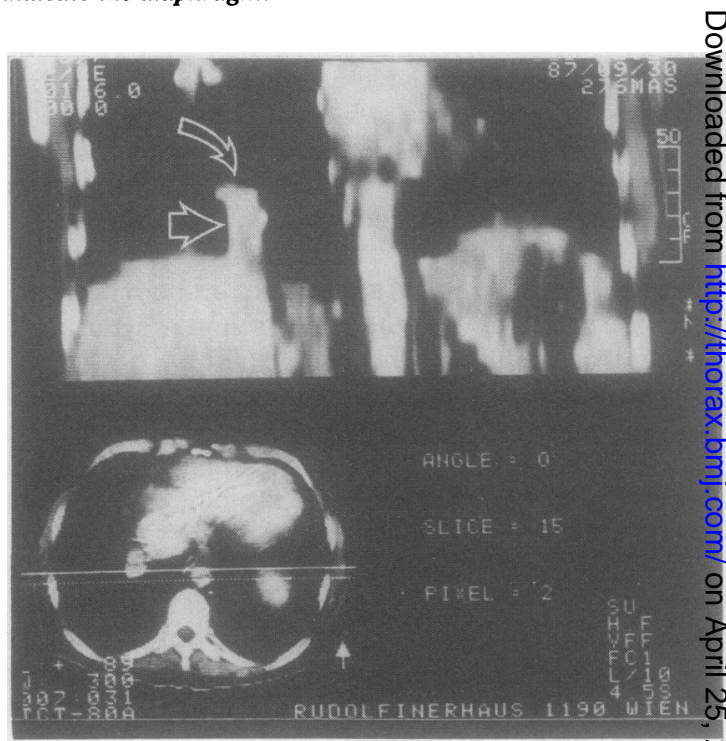

Fig 3 Computed tomography scan (reconstructed coronary image) showing the scimitar vein (arrows) running down to the diaphragm.

Pulmonary artery pressures were normal.

The atypical vein could not be seen sufficiently wello by angiography, so computed tomography was car ried out. On reconstructed images the anomalous vein could be visualised descending to the diaphragm (fig 3). The patient refused surgical treatment, so sympo tomatic treatment was started and she was discharged. 
Anomalous pulmonary venous drainage shown by duplex sonography, computed tomography, and radiography 65

\section{Discussion}

Our patient showed signs of right heart failure, which was caused by the scimitar syndrome. In this case the radiographic presentation of the scimitar vein was unusual in that it was clearly visible on the lateral chest radiograph, whereas on the posteroanterior radiograph the vein was only faintly visible near the diaphragm.

Oakley et at have described the sonographic appearance of the abnormal vein entering the inferior vena cava. Duplex sonography, however, has not to our knowledge been used previously to determine blood flow in this vessel. The method allowed the presence of venous flow to be verified. The scimitar vein $^{310}$ can also be demonstrated by computed tomography but sometimes difficulties occur in identifying its site of entry into the inferior vena cava.

When the point of insertion can be shown by sonography, catheter studies are not necessary to locate the vein itself (which may be difficult), though the studies help to estimate the size of the shunt, to measure the pulmonary artery pressure, and to rule out additional septal defects of the heart.

\section{References}

1 Fraser RG, Paré PJA. Diagnosis of diseases of the chest. Vol 1. Philadelphia: Saunders, 1977:631.

2 Folger GM. The scimitar syndrome. Angiology 1976;27: 373-407.

3 Godwin JD, Tarver RD. Scimitar syndrome: four new cases examined with CT. Radiology 1986;159:15-20.

4 Neill CA, Ferencz C, Sabiston DC, Sheldon H. The familiar occurrence of hypoplastic right lung with systemic arterial blood supply and venous drainge: "scimitar syndrome." Bull Johns Hopkins Hosp 1960; 107:1-21.

5 Clements BS, Warner JO, Shinebourne EA. Congenital bronchopulmonary vascular malformations: clinical application of a simple anatomical approach in 25 cases. Thorax 1987;42:409-16.

6 Oakley D, Naik D, Verel D, Rajan S. Scimitar vein syndrome: Report of nine new cases. Am Heart J 1984;107:596-8.

7 Haworth SG, Sauer U, Buelmeyer K. Pulmonary hypertension in scimitar syndrome in infancy. Br Heart $J$ 1983;50:182-9.

8 Canter CE, Martin TC, Spray TL, Weldon CS, Strauss AW. Scimitar syndrome in childhood. Am J Cardiol 1986;58:652-4.

9 Beitzke A, Gypser G, Sager WD. Scimitarsyndrom mit Hufeisenlunge. Fortschr Roentgenstr 1982;136:265-9.

10 Olson MA, Becker GJ. The scimitar syndrome: CT findings in partial anomalous pulmonary venous return. Radiology 1986;159:25-6. 